\title{
Evaluation of Two Different Attachment Systems Used with Mandibular Implant-Retained Overdenture
}

\author{
Mohamed Y Abdelfattah ${ }^{1,2}$, Mohammed K Fahmi ${ }^{3}$
}

${ }^{1}$ Department of Prosthodontics, Faculty of Dentistry, Tanta University, Egypt, ${ }^{2}$ Department of Prosthodontics, Faculty of Dentistry, Taif University, Kingdom of Saudi Arabia, ${ }^{3}$ Department of Restorative Dental Materials, Faculty of Dentistry, Taif University, Kingdom of Saudi Arabia

\begin{abstract}
Objectives: The aim of this study was to evaluate the effect of two different attachment systems on the retention and implant stability of implant retained mandibular Overdenture.

Material and Methods: Fourteen completely edentulous patients with age ranged from 47-65 years planned to receive conventional complete denture. Following the treatment protocol, each patient received two implants in the mandibular anterior region and after insurance of the osseointegration, the patients were randomly divided into two groups; Group (A) received Ball/O-Ring attachment and Group (B) received Locator attachment. The retention of two groups were assessed by the digital forcemeter at 3 times $(\mathrm{T})$; $\left(\mathrm{T}_{0}\right)$ retention of the conventional complete denture, $\left(\mathrm{T}_{1}\right)$ at time of insertion of implant retained mandibular overdenture and ( $\left.\mathrm{T}_{3}\right)$ retention after three months of insertion of implant retained mandibular overdenture. The implant stability quotient (ISQ) was done using Magnetic Resonance Frequency Analyzer (Osstell, ISQ) at the time of loading then after 3 and 6 months.

Results: The retention values before the insertion of overdenture $\left(\mathrm{T}_{0}\right)$ were considerably low in comparison with those at time of insertion of overdenture $\left(T_{1}\right)$ and after 3 months from denture insertion $\left(T_{3}\right)$. Regarding the ISQ values, there were no significant difference between the two groups before and at the time of insertion of the implant while there was a significant difference between two groups with better stability resulted in the Locator attachment group after three months $(\mathrm{p}<0.05)$.

Conclusion: Within the limitation of this study, both types of attachment systems; Ball/O Ring and Locator attachments, are reliable modalities for improving the retention and stability of implant retained mandibular overdenture with superior initial stability results for the Locator attachment.
\end{abstract}

Key Words: Implant retained overdenture, Implant stability, Locator attachment, Retention, Stud attachment, Resonance frequency analysis

\section{Introduction}

Prosthetic rehabilitation with complete denture is the most well-known treatment for edentulous state and its advantages and disadvantages have been explained and discussed [1]. The successful incorporation of the denture with the patient's oral functions in addition to the psychological acceptance of the dentures by the patient is important factors to achieve favorable results of complete denture treatment [2].

Different researches have confirmed that conventional mandibular dentures can't restore masticatory function, or enhance patient satisfaction and the quality of life [3]. Retention and stability problems of the mandibular complete denture affect the oral function and masticatory functions. To overcome these problems, the prosthetic management using Implant-retained overdentures is extremely valuable [4,5]. Rehabilitation with mandibular implant-tissue-supported overdentures using two implants can be considered the main treatment modality when more implant can't be placed [6].

Many types of attachments can be used with implant overdentures such as magnets, Ball/O-ring, bar(s)/clip(s) and Locator attachments. To guarantee sufficient stability, finest shape, form, appearance, and comfort, the overdentures should be cautiously planned [7]. The inter-arch space, stress distribution between implant and mucosa, and the amount of retention and resistance needed are the main factors affecting attachment systems selection [8].

The simplicity of use and maintenance of Ball/O-ring, its low cost, elimination of a superstructure bar, its wide range of movement, and great patient satisfaction are the main advantages of Ball/O-ring which make it one of the most successful stud attachments to enhance the retention of implant and tooth supported complete and partial overdentures. On the other hand, it wears over time, steadily loses retention, and must be changed from time to time and the ball attachments must be parallel to each other [9].

The advantages of the Locator attachment are its selfaligning, has double retention, rotational action, built-in guide planes providing precise insertion; it can also be used in nonparallel situations, can be used in cases with reduced interarch spaces and is available in different colors with different retention values; resilient, retentive, and durable. Besides, its repair and replacement are easy and fast [10].

Implant stability is very important for dental implants success and it is provided initially by mechanical engaging in the implant bed bony walls. Secondary stability occurs during healing by deposition of bone on the implant surface (osseointegration) [11]. Different methods such as percussion and mobility testing have been accustomed to measure implant stability which uses the application of lateral forces with mirror handles, measuring cutting torque resistance, reverse torque tests, insertion torque values, dental fine tester, periotest, and Osstell electronic device. The Osstell instrument is a modern, non-invasive and a relatively precise technique, which enables the measuring using resonant frequency analysis (RFA) and provides both information on implant stability in the bone and reliable guidance to further course of implant therapy [12]. 
There are limited clinical data evaluating retention of the prosthesis and implant stability when Ball/O-ring attachment and Locator attachments are used with two implant supported anterior overdenture. So, the aim of this study was to compare the effect of attachment type (Dentium Ball/O-ring attachment and Zest Locator) on implant stability and retention of mandibular implant overdentures.

\section{Materials and Methods}

Fourteen completely edentulous male patients, ranging from 47 to 65 years of age were assigned in current research according to the following criteria: At least one year of Total edentulism in the maxilla and the mandible, mandibular residual alveolar ridge of at least $12 \mathrm{~mm}$ height and $6 \mathrm{~mm}$ width at the canine region, covered with firm, relatively even compressible mucosa, and Angle's class I maxillomandibular relations with adequate inter-arch space. While the exclusion criteria included: any systemic disease that may affect bone and soft tissue health, TMJ disorders, abnormal habits, e.g. bruxism and clenching, Smokers, history of radiation therapy in the head and neck region, Un-cooperative patients. Any logistic, psychiatric or physical reasons that could affect follow-up, and lack of motivation for adequate home care.

The study was planned and performed at the specialty clinics of Prosthodontic Department, Faculty of Dentistry, Taif University in accordance with Declaration of Helsinki and approved by the Research and Ethics Committees in Faculty of Dentistry, Taif University. After the patients were informed about the line of treatment and need of their regular and frequent recall, they approved their treatment plan on a written consent to follow the study protocol throughout the total period of the research.

Routine medical and dental investigations were performed for each patient. Preoperative radiographic planning of the implant sites were conducted using Cone Beam Computed Tomography (CBCT) and a replica of the patient's lower denture.

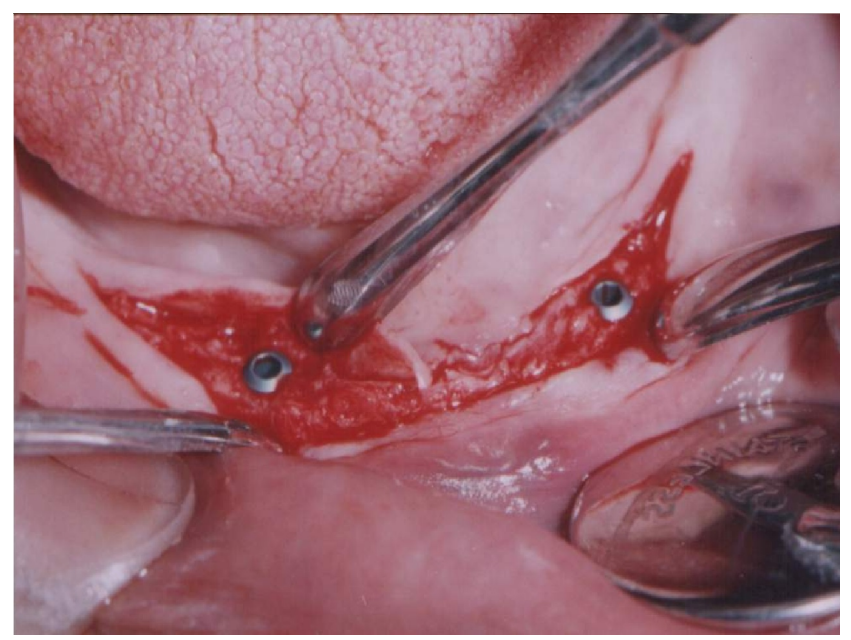

Figure 1. Cover screws were screwed into the fixtures.

Following the conventional two-stage surgical approach (Figure 1) the patient received two identical implant fixtures (Self tapping Vacuum Titanium Plasma Sprayed (VTPS) implant (PITT-EASY-Implant, Oraltronics, Bremen, Germany) with the same length $(10 \mathrm{~mm})$ and diameter $(4 \mathrm{~mm})$ in the mandibular anterior region with low speed, high torque drilling and double coolant preparation of implant osteotomy sites. The flap was sutured by continuous mattress suture using 3/zero black silk (M-Natur, International sutures manufacturing Co. Egypt).

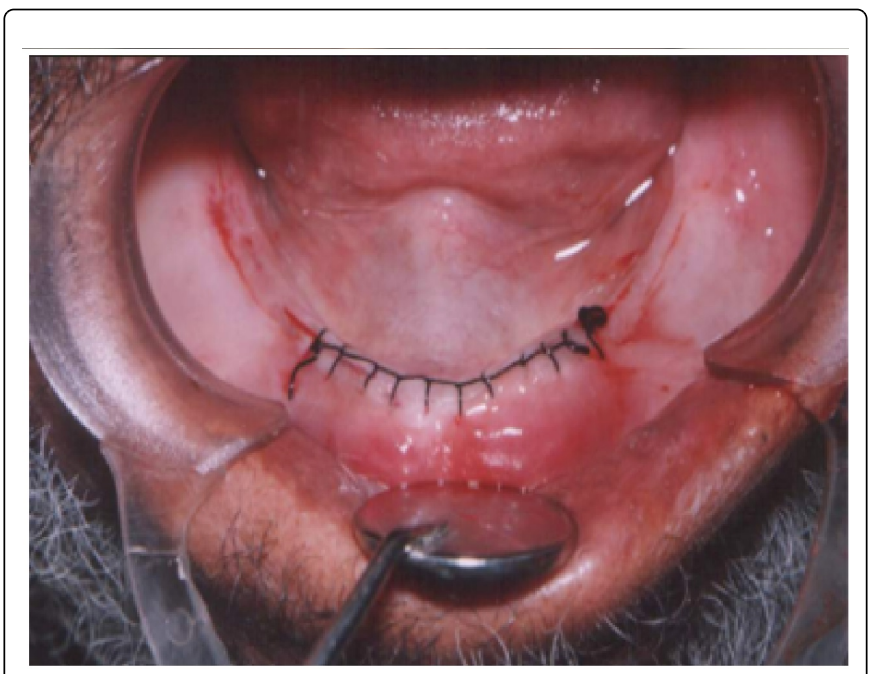

Figure 2. Continuous matrix suture of the mucoperiosteal flap.

(Figure 2) and the patients were informed about postsurgical care, medications, and instructions. One week later, the old dentures were relieved at the implant sites and relined with tissue conditioner material (Alpha-dent, Alphadental products Co., Chicago, USA) and used for 3 months healing period.

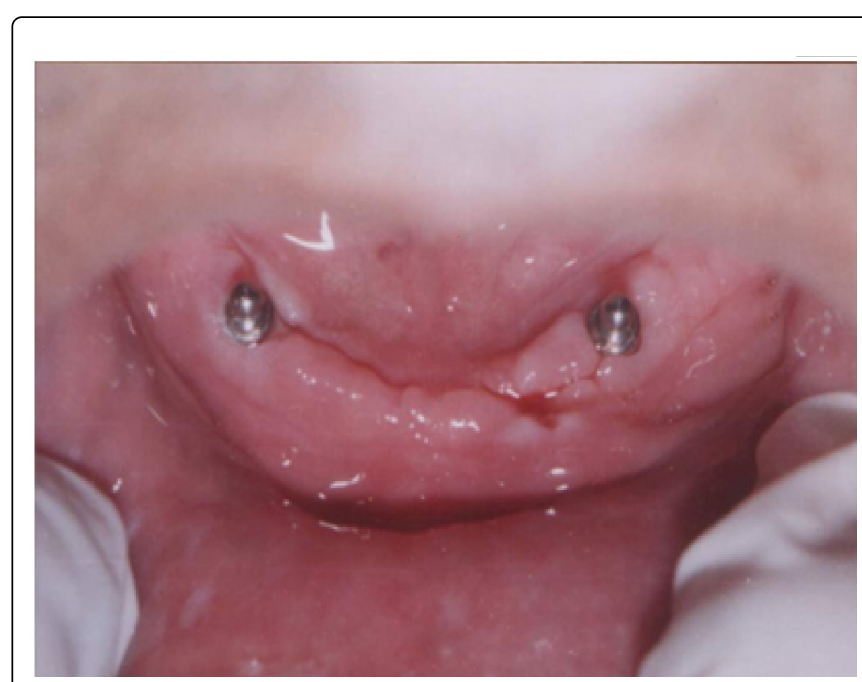

Figure 3. Ball abutments screwed into the fixture.

After the 3 months of the healing period, hex driver was used to lose the cover screws after then for seven days healing abutments were screwed to the implants. After the removal of healing abutments, the patients were divided randomly with respect to the type of attachment used into two equal groups each consisting of 7 patients. 


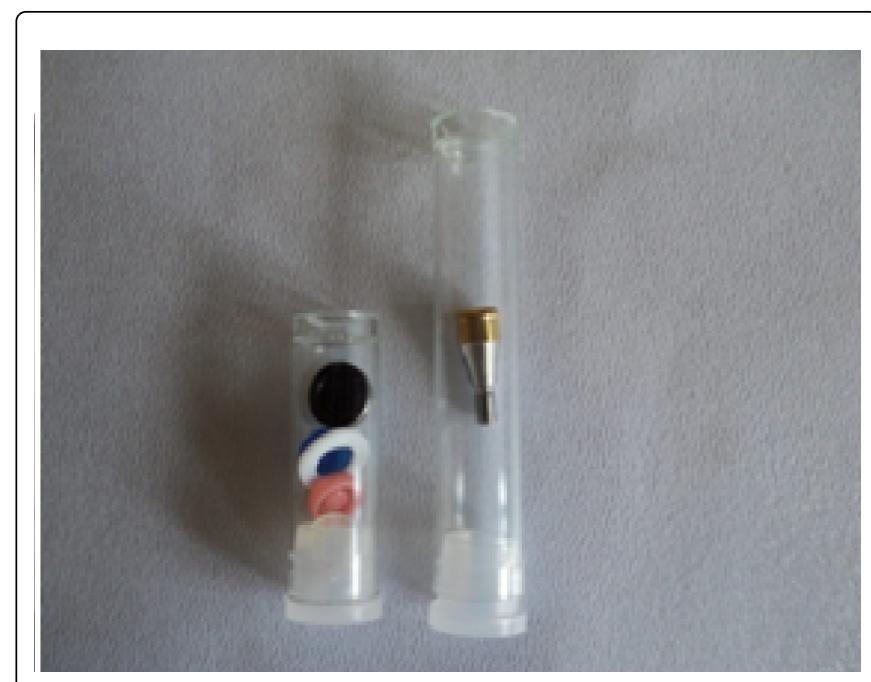

Figure 4a. Zest Locator attachment system.

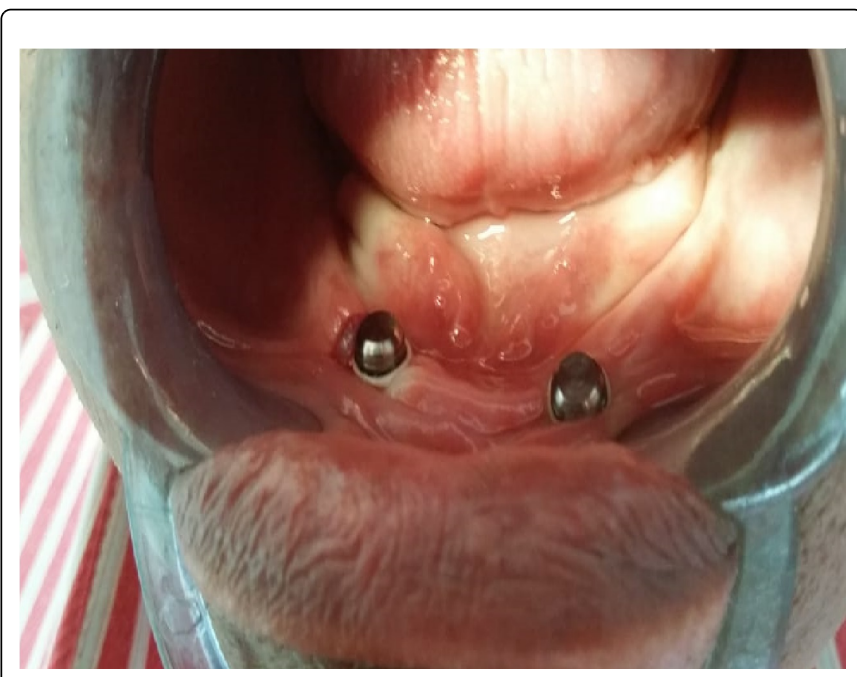

Figure 4b. Locator abutments with block out spacer at time of loading.

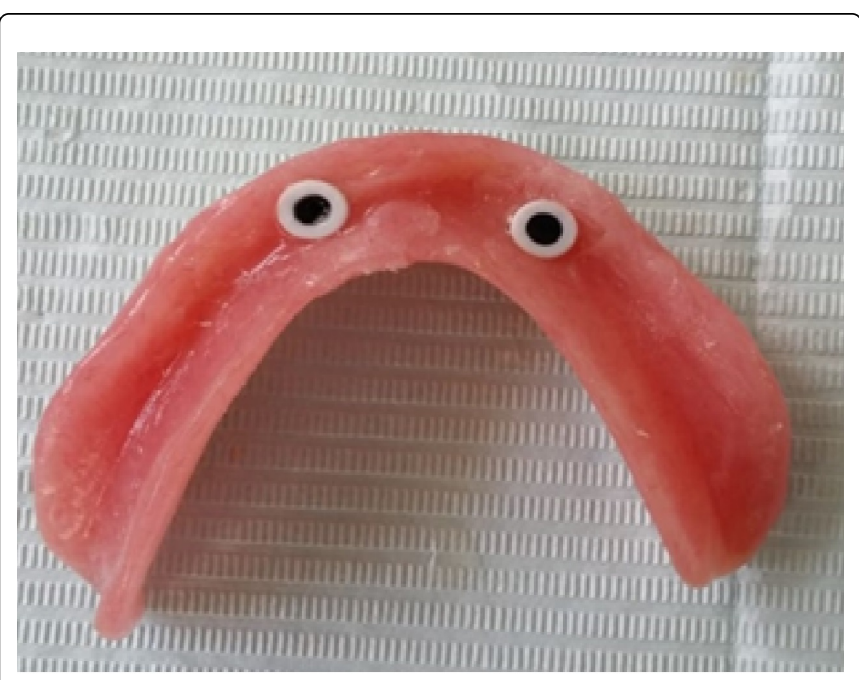

Figure 5. O-ring inserted into their sleeves inside the metal houses.

Patients those who received mandibular overdenture retained by Ball/O-ring attachment system (Dentium Co,
Korea) (Figure 2) were assigned to Group 1 and those who received by Locator attachment system (Zest dental solutions, USA) (Figures 3, 4a and 4b) were grouped to Group 2.

A direct intraoral pick-up technique was used to integrate matrices of the Ball attachments and Locator attachments into dentures. The technique used a cold-curing, MMA free, hard relining material for chairside relining in one single session (Hardliner CD, Promedica, Germany), in order to prevent adherence of the acrylic resin to the implant a block out spacer was used (Figure 5).

\section{Evaluation}

\section{Retention}

The retention of two groups was assessed at 3 times $(\mathrm{T}) ;\left(\mathrm{T}_{0}\right)$ retention of the conventional complete denture, $\left(\mathrm{T}_{1}\right)$ at time of insertion of implant retained mandibular overdenture and $\left(\mathrm{T}_{3}\right)$ retention after three months of insertion of implant retained mandibular overdenture. The digital forcemeter device was used to measure the retention of the mandibular complete overdenture. Metal hooks were placed in the buccal surface of mandibular denture flange. A $0.9 \mathrm{~mm}$ orthodontic wire with cold- curing acrylic resin was placed towards the buccal side of the $2^{\text {nd }}$ premolar and $1^{\text {st }}$ molar area so that a vertical displacing force could be exerted on the denture by the forcemeter device and can test its retention. The shaft of the forcemeter device was placed with the hook attachment and the hook occupied the center of the wire loop (Figure 6).

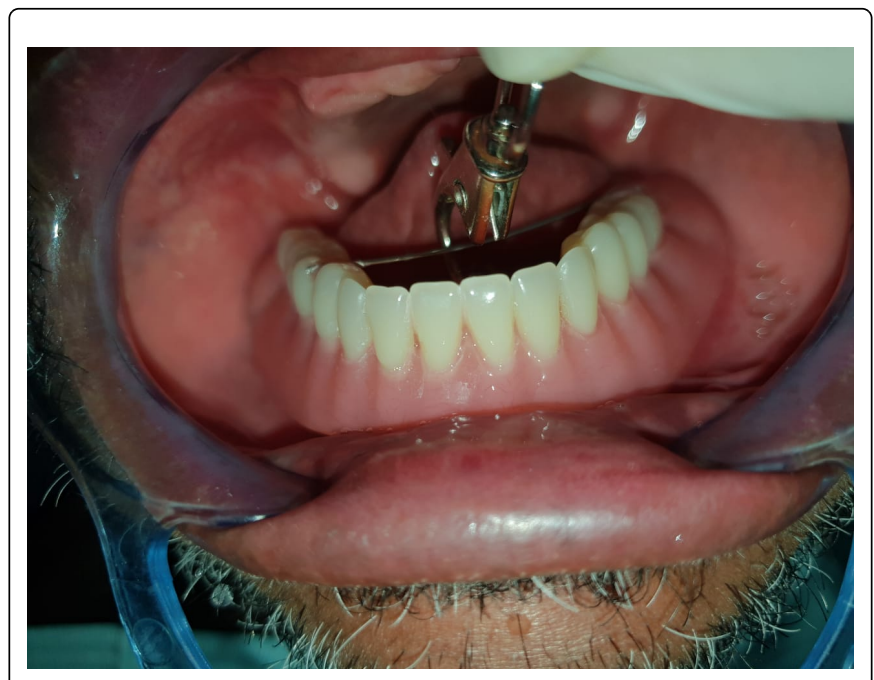

Figure 6. Patient during measuring retention.

$0.9 \mathrm{~mm}$ orthodontic wire was connected to the pull end of the forcemeter device; a vertical force was applied to pull the device in the vertical direction until the detachment of the denture was performed with the denture detachment the force reading was recorded in Newton. For each patient, more than three records were taken each time and divided to get the average [13].

\section{The implant stability}

To measure the implant stability quotient (ISQ) Magnetic Resonance Frequency Analyzer (Osstell ISQ, Gote- borg, Sweden) (Figure 7) was used at the time of loading. 


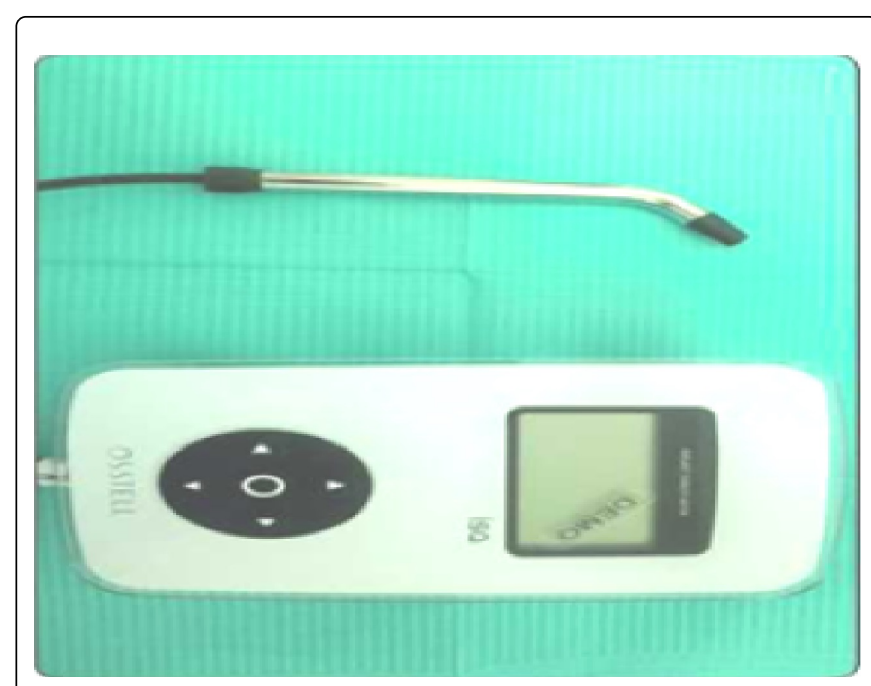

Figure 7. Osstell ISQ device.

A special smart peg was then connected after 3 and 6 months to the implant body at a torque of $4-5 \mathrm{~N} / \mathrm{cm}$ and measurements were made at a distance of $2-3 \mathrm{~mm}$ such that the probe tip of the analyzer points the small magnet present above the smart peg. Measurements were made at buccolingual and mesiodistal directions (Figure 8). Repetition of the measurements was performed 3 times to guarantee the result and study, at last, the mean was calculated and used for statistical analysis.

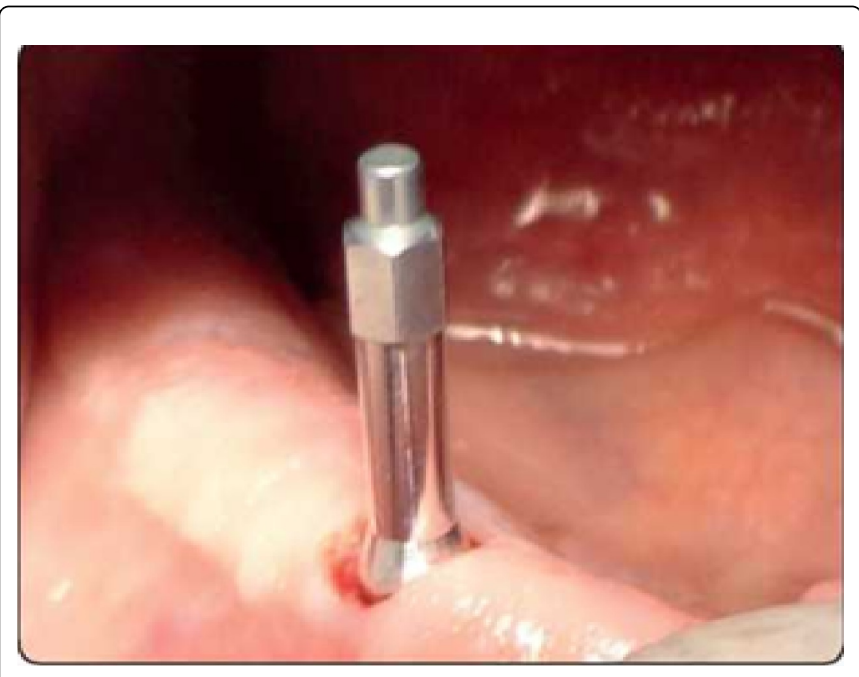

Figure 8. Smart peg connected to the implant for ISQ measurement.

\section{Statistical analysis}

The collected data were analyzed using SPSS 20.0 (Statistical Package for Social Sciences) for Windows. Kolmogorov Smirnov test was used as a test for normality and the independent sample t-test was used to compare the two groups, the statistical significance level was set at $\mathrm{P}<0.05$.

\section{Results}

All the 14 implants in this study were considered successfully osseointegrated as they show no signs of peri-implant pathology and successful rigid fixation clinically and radiologically.

Table 1 shows the retention values (R) of the 2 groups at different observation times. The data present at $\mathrm{T}_{0}$ i.e. before overdenture insertion showed no statistically significant difference between group I and group II while at the time of loading $\left(\mathrm{T}_{1}\right)$ a statistically significant difference was observed, and after 3 months' time $\left(\mathrm{T}_{3}\right)$ the mean values for the group I was higher than that of the group II $(\mathrm{P}<0.05)$.

Table 1. Retention values in the two groups.

\begin{tabular}{|c|c|c|c|}
\hline & (T0) & (T1) & (T3) \\
\hline Group IX \pm SD & $2.54 \pm 0.60$ & $8.46 \pm 0.72$ & $8.35 \pm 0.71$ \\
\hline Group II X \pm SD & $2.3 \pm 0.50$ & $5.6 \pm 0.55$ & $5.11 \pm 0.8$ \\
\hline (p value) & 0.09 & $0.003^{*}$ & $0.004^{*}$ \\
\hline \multicolumn{4}{|c|}{ *Significant at $5 \%$ c level of significance } \\
\hline \multicolumn{2}{|c|}{$\begin{array}{l}\text { Group I: Dentium Ball/O-ring attachment } \\
\text { system }\end{array}$} & \multicolumn{2}{|c|}{$\begin{array}{l}\text { Group II: Zest Locator } \\
\text { attachment system }\end{array}$} \\
\hline \multicolumn{2}{|c|}{$\left(T_{0}\right)$ Before overdenture Insertion } & \multicolumn{2}{|c|}{$\begin{array}{l}\left(T_{1}\right) \text { At time of overdenture } \\
\text { insertion }\end{array}$} \\
\hline \multicolumn{2}{|c|}{$\left(T_{3}\right) 3$ months after overdenture insertion } & & \\
\hline
\end{tabular}

The mean ISQ values for both of the groups have been presented in the Table 2. A subsequent decrease in the ISQ values for the Group (I) resulted from the time of loading $(\mathrm{ISQ}=69.06)$ to the $3^{\text {rd }}$ month $(\mathrm{ISQ}=68.21)$ followed by an increase in value from the $3^{\text {rd }}$ month to the $6^{\text {th }}$ month $(\mathrm{ISQ}=71.25)$.

Table 2. Mean ISQ Values at Different Intervals

\begin{tabular}{|l|l|l|l|l|}
\hline & & \multicolumn{3}{|l|}{$\begin{array}{l}\text { Statistical } \\
\text { Analysis }\end{array}$} \\
$\begin{array}{l}\text { Follow unterval } \\
\text { Int }\end{array}$ & $\begin{array}{l}\text { Group I Mean } \pm \\
\text { SD }\end{array}$ & $\begin{array}{l}\text { Group II Mean } \pm \\
\text { SD }\end{array}$ & $\mathbf{t}$ & $\mathbf{p}$ \\
\hline $\begin{array}{l}\text { At the time of } \\
\text { Loading }\end{array}$ & $69.06 \pm 5.11$ & $70.25 \pm 5.21$ & 0.564 & 0.578 \\
\hline 3rd Month & $68.21 \pm 3.76$ & $71.75 \pm 4.44$ & 2.108 & $0.047^{*}$ \\
\hline 6th Month & $71.25 \pm 3.98$ & $73.00 \pm 4.02$ & 0.96 & 0.295 \\
\hline * statistically significant at $p<0.05$ & & \\
\hline Group I: Dentium Ball/O-ring attachment system \\
\hline Group II: Zest Locator attachment system \\
\hline
\end{tabular}

On another side a throughout increase in the mean ISQ values resulted for the Group II from the time of loading (ISQ=70.25) to (ISQ=73.00) 6 months. While comparing the results of both the groups it was found that a statistically significant difference was there at the $3^{\text {rd }}$ month follow up $(\mathrm{p}=0.047)$ and no statistical significance was found after 6 months of follow up at $\mathrm{p}<0.05$.

\section{Discussion}

Fourteen patients aged between 47-65 years were selected for the study as it is found with the advancing age the success rate can be less than optimal [14]. 
A standardized implant size was used as a variation in the length or the diameter of the implant may affect the biomechanics of dental implant [15].

Salvi et al stated that the modalities used to evaluate oral implants during maintenance care should be highly sensitive, easy to measure and should create reproducible data [16].

Retention was measured in Newton using forcemeter before insertion of overdenture $\left(\mathrm{T}_{0}\right)$, at time of insertion $\left(\mathrm{T}_{1}\right)$ and three months $\left(\mathrm{T}_{3}\right)$ after overdenture insertion. At each time, 5 records, with one-minute rest between each reading, were registered and take the average for each patient [13].

To measure the stability of the implant many different techniques have been introduced such as measuring cutting torque resistance, reverse torque tests, dental fine tester, percussion, and mobility testing, periotest, insertion torque values, and histomorphometric and histologic analysis of the bone-implant interface. However, these techniques face drawback in terms of accuracy, reliability, and nature (invasive or destructive). Based on resonant frequency analysis [17]. Osstell electronic device measures the stability of the implant and quantify its ISQ values [18]. The Osstell instrument facilitates optimizing implant healing, prosthetic construction, and surgical protocol. Repeated measurements of implant stability can be taken from the instrument, at the time of placement, healing, and on and after loading helping clinician to detect any instability in the implant and facilitating them to take any preventive measures prior to implant failure [19].

This study results revealed that the retention values showed no statistically significant difference between group I and group II before overdenture insertion $\left(\mathrm{T}_{0}\right)$ while it was there at the time of loading $\left(\mathrm{T}_{1}\right)$ and after 3 months $\left(\mathrm{T}_{3}\right)$ with higher mean values for group I when compared to group II $(\mathrm{P}<0.05)$.

Regarding the findings of the implant stability, in accordance with other researches, with an increase in boneimplant contact area the ISQ values showed an increase with time [20]. Comparing the ISQ results of both groups, it was found that after loading with higher values for the Locator group at the $3^{\text {rd }}$ month there was a significant difference between both the groups while at other follow up periods no such difference was found. This can be explained by the difference in stiffness of the retentive components of the two systems and that the Ball/O-ring system relocates high bending forces to the implants under lateral forces [21,22].

\section{Conclusion}

Both the Ball/O-ring and Locator attachment systems are successful and useful. Regarding the retention, there was no statistically significant difference between group I and group II before overdenture insertion $\left(\mathrm{T}_{0}\right)$ while there was a statistically significant difference between them at the time of loading $\left(\mathrm{T}_{1}\right)$ and after 3 months $\left(\mathrm{T}_{3}\right)$ with higher mean values for the group I than group II $(\mathrm{P}<0.05)$. However, the Group II showed superior initial stability results than Group I.

\section{Declaration}

\section{Ethics approval and consent to participate}

We took the approval of the ethics committee in Tanta University that approved the study. And each patient participated in this study signed a consent to participate in this study.

\section{Consent for publication}

Consent to publish was obtained from persons participated in this study.

\section{Availability of data and material}

The datasets used and/or analyzed during the current study are available from the corresponding author on reasonable request.

\section{Competing interests}

The authors declare that they have no competing interests in this section.

\section{Funding}

The authors declare that there have no funding sources for this study, only the authors pay all the fundings.

\section{Authors' contributions}

Mohamed Y Abdelfattah constructed facial prosthesis to some patients, contacted all patients, shared in study design, distribute the questionnaire to the patients, received their responses and was a major contributor in writing the manuscript.

Mohamed K Fahmi shared in study design, analyzed, and interpreted the collected data.

\section{Acknowledgments}

Not applicable

\section{References}

1. Carlsson GE. Clinical morbidity and sequelae of treatment with complete dentures. Journal of Prosthetic Dentistry. 1998; 79: 17-23.

2. Toshio H, Masakazu M, Naoyuki S, Yoshikazu Y. Influence of denture treatment on brain function activity. Japanese Dental Science Review. 2011; 47: 56-66.

3. Frometin $\mathrm{O}$, Lassauzay $\mathrm{C}$, Abi Nader $\mathrm{S}$, Feine $\mathrm{J}$, de Albuquerque Junior RF. Testing the retention of attachments for implant overdentures validation of an original force measurement system. Journal of Oral Rehabilitation. 2010; 37: 54-62.

4. Vasant R, Vasant MK. Retention systems for implant-retained overdentures. Dental Update. 2013; 4: 28-31.

5. Fontijn FA, Slagter AP, van-der Bilt A, Van 'TH, Witter DJ. Biting and chewing in overdentures, full dentures, and natural dentitions. Journal of Dental Research. 2000; 79: 1519-1524.

6. Laurito D, Lamazza L, Michael J Spink, Alberto De Biase. Tissue-supported dental implant prosthesis (overdenture) the search for the ideal protocol: A literature review. Annali di stomatologia (Roman). 2012; 3: 2-10. 
7. Evtimovska E, Masri R, Driscoll CF, Romberg E. The change in retentive values of locator attachments and Hader clips over time. Journal of Prosthodontics. 2009; 18: 479-483.

8. Mentag P, Kosinski T. A clinical case illustrating a new implant. Dentistry Today. 1991; 10: 48-49.

9. Winkler S, Piermatti J, Rothman A, Siamos G. An overview of the O-ring implant overdenture attachment: Clinical reports. Journal of Oral Implantology . 2002; 28: 82-86.

10. Kleis WK, Kammerer PW, Hartmann S, Al-Nawas B, Wagner W. A comparison of three different attachment systems for mandibular two-implant overdentures: one-year report. Clinical Implant Dentistry and Related Research. 2010; 12: 209-218.

11. Huwiler MA, Pjetursson BE, Bosshardt DD, Salvi GE, Lang NP. Resonance frequency analysis in relation to jawbone characteristics and during early healing of implant installation. Clinical Oral Implants Research. 2007; 18: 275- 280.

12. Sennerby L, Meredith N. Implant stability measurements using resonance frequency analysis: biological and biomechanical aspects and clinical implications. Periodontology 2000. 2008; 47: 51-66.

13. Burns DR, Unger JW, Coffey JP, Waldrop TC, Elswick RK. Randomized, prospective, clinical evaluation of prosthodontic modalities for mandibular implant overdenture treatment. Journal of Prosthetic Dentistry. 2011;106: 12-22.

14. Porter JA, von Fraunhofer JA. Success or failure of dental implants? A literature review with treatment considerations. General Dentistry. 2005; 53: 423-432.

15. Meijer HJ, Kuiper JH, Starmans FJ, Bosman F. Stress distribution around dental implants: influence of superstructure, length of implants, and height of mandible. Journal of Prosthetic Dentistry. 1992; 68: 96-102.

16. Salvi GE, Lang NP. Diagnostic parameters for monitoring peri-implant conditions. The International Journal of Oral and Maxillofacial Implants. 2004; 19: 116-127.

17. Meredith N. Assessment of implant stability as a prognostic determinant. The International Journal of Prosthodontics. 1998; 11: 491-501.

18. Sennerby L, Meredith N. Implant stability measurements using resonance frequency analysis: biological and biomechanical aspects and clinical implications. Periodontology 2000. 2008; 47: 51-66.

19. Herrero-Climent M, Santos-Garcia R, Jaramillo-Santos R, Romero-Ruiz MM, Fernandez-Palacin A, et al. Assessment of Osstell ISQ's reliability for implant stability measurement: A crosssectional clinical study. Medicina Oral Patologia Oral y Cirugia Bucal. 2013; 18: 877-882.

20. Karakoca-Nemli S, Aydin C, Yilmaz H, Sarisoy S. Stability measurements of craniofacial implants by means of resonance frequency analysis: 1-year clinical pilot study. The International Journal of Oral and Maxillofacial Implants. 2012; 27: 187-193.

21. Fanuscu MI, Caputo AA. Influence of attachment systems on load transfer of an implant-assisted maxillary overdenture. Journal of Prosthodontics. 2004; 13: 214-220.

22. Ibrahim A. Evaluation of low profile attachments for implant-retained mandibular overdentures in restoring cases with limited interarch space. Cairo Dental Journal. 2009; 25: 191-203. 